\title{
Selection of Tower Crane using Multi-Criteria Decision-Making Techniques
}

\author{
Devika Nayal \\ Department of Building Engineering and Management \\ School of Planning and Architecture, \\ New Delhi
}

\author{
Prof. Dr. Virendra Kumar Paul \\ Department of Building Engineering and Management \\ School of Planning and Architecture \\ New Delhi
}

\author{
Kuldeep Kumar \\ Department of Building Engineering and Management \\ School of Planning and Architecture \\ New Delhi
}

\begin{abstract}
Within the range of equipment used at site, owing to its extensive usage, it is stated in various literature that the tower crane becomes a pivotal equipment at site and its optimal performance at minimal cost is most desired. Due to the importance of tower cranes at site, this paper proposes a system of selection of tower cranes at site using multi-criteria decisionmaking (MCDM) model for the same. The study also attempts to apply the model on a case study, finding of which shall be presented in the report. The methodology adopted for the selection is Technique of Order Preference Similarity to the Ideal Solution (TOPSIS) method and the result have been compared against those obtained by Multicriteria Optimization and Compromise Solution (VIKOR) and Simple Additive Weighing (SAW). The technique selected for MCDM is as crucial as the factors considered for selection since the results may vary. Hence, on the basis of this variation, more than one MCDM technique can be employed for a better understanding of the suitability of the equipment.
\end{abstract}

Keywords-Cranes, Tower Cranes, Multi Criteria Decision Making, TOPSIS, VIKOR

\section{INTRODUCTION}

The selection of an appropriate tower crane is crucial for the success of complex and mechanized construction projects that are being handled currently. This issue of selection has been addressed by various scholars in order to improve the frame work that assists decision makers to make better judgement. A wrongly chosen tower crane is likely to cause severe issues along with cost escalation as once it has been installed, the pace of construction and the work practice is highly influenced by the performance of the tower crane [1].

\section{A. Impact of Crane Selection on Construction Activities}

The key determinants of productivity of the tower crane can be broadly considered as the capability of the crane to arrive at the source or destination within the given time and carrying the given quantity with a movement that meets certain quality parameter. Thus, the factors affecting productivity of the crane are those of loading time, time taken to lift the material, unloading time and time taken to return to the material source. This completes a crane cycle. Any delay within the crane cycle directly affects the schedule of works to be carried out further as a delayed material supply can have a cascading effect on the construction activities. The time taken to hoist the material is a variable in most cases as the height for material transfer along with the angle of placement is largely dependent on the relative location of source and destination for materials. Further, while calculating the efficiency of tower cranes it has been observed that working time of a crane is significantly lower than the total operating time of crane; dropping the efficiency to as low as $25 \%$ in one case and lower than $60 \%$ in other two cases. They have attributed this lack of efficiency to idle worker time and waiting time [2]

Thus, shortlisting of an appropriate tower crane for given work is rather multifarious and a fairly complex analysis which requires a well-established selection process to be followed. Due to this complexity of the selection process, employing a mathematical tool for such tasks becomes important for a rational consideration of various factors affecting the use of equipment. Coupled with the analysis of crane operation, both the selection and analysis can contribute to development of a holistic framework for optimal performance of tower crane in construction.

There are numerous operational research (OR) techniques which are used in the selection of equipment. Multi-Criteria Decision-Making or MCDM and other suitable techniques for selection of equipment are employed by various scholars as further discussed in the literature review [3]. MCDM is considered a useful tool to help quantification of subjective parameters. A detailed description of the same is provided in subsequent sections.

This paper, thus, presents a quantitative methodology to select tower crane considering its productivity and other operational parameters. The methods presented in this paper shall be illustrated with a case example

\section{B. Application of MCDM in Crane Selection}

The tower cranes used in construction are steadily advancing in technology and the output is resulting in wider range of tools available to undertake the required activities. If overlooked, the selection of these equipment can also negatively impact productivity and flexibility and thus it is important to shortlist the most suitable equipment based on project requirement. This requires a decision support system and parameters for selection of such machines that can allow 
the decision makers to be able to access the appropriate machine for a given situation [4].

\section{Research Objectives}

The aim of this study is to formulate a decision matrix and evaluate the same on a case study using MCDM technique for selection of a tower crane. The following research objectives have been identified in order to achieve this aim:

1. To list factors affecting tower crane through literature study and select the relevant tower cranes to be considered for evaluation in this study

2. To shortlist appropriate multicriteria decision making MCDM method for analysis through literature on application of MCDM

3. To prepare a decision matrix and apply the selected MCDM method to determine the most suitable tower crane for a given project

\section{LITERATURE REVIEW}

\section{A. Factors Affecting Tower Crane Operation}

While planning and selection of heavy equipment the authors emphasized on engine type and power, speed, operational pressure, machine dimensions, fuel consumption, type of transmission, maintenance details, weight, warranty period etc [5]. Another study focuses on the technical parameters of the crane, namely: geometry of the carriers, the outriggers and counterweight dimensions [6]. [7] considered the parameters such as performance measures, technical aspects, economic and strategic aspects. Within the paper by [8], alternatives were evaluated against the cost criteria of ownership or rental cost, maintenance, taxes, licenses or insurance related cost, cost of transportation of equipment to site along with cost for erecting and dismantling. It has been pointed out that equipment productivity is key factor in selection of the equipment along with ownership and operational cost, characteristics of the equipment along with the operating life [9]. Another study has used parameters such as fixed cost of running the machinery per hour, the variable cost of the operation, speed, dimensions of the equipment, weight and flexibility [10]. A research uses criteria such as weight, dimension of the crane, type of the lifting that was to be undertaken, conditions of site, supporting surfaces, accessibility and stability of the terrain, area available for working and operating clearances [11]. In a study, the factors chosen are applicability, safety and economy [12]. There are studies that also focus on the selection of sustainable construction equipment with respect to energy conservation and considered factors such as emissions of greenhouse gas, consumption of fossil fuel, energy saving, noise and vibration control [13].

Another paper on selection of tower crane have emphasized on factors such as operational, environmental, economic and strategic considerations [14]. Research has also mentioned that selection of crane shall be based on type of material to be handled, attributes of the movement along with imposed site restrictions, safety and cost [15]. Studies focus equipment parameters and characteristics along with operating conditions for selection of the equipment [16]. A paper by [17] consider performance, risk and environmental impact while exploring techniques for selection of cranes. One of the researches considered have used factors based on technical criteria, cost, maintenance and machine operation as a part of their study on selection of tower crane [18]. [19] has mentioned factors such as cost, space occupied, technical criteria, maintenance, flexibility, safety, environmental impact in their paper on literature review of factors affecting selection of tower crane.

In the paper, the factor that has been utilized the most for selection of crane and material handling equipment is given priority while the factors that have been mentioned the in the least number of papers, have been ignored. A summary of list of factors and their frequency of repetition is presented below and Pareto Analysis have been applied on the factors to shortlist those that are relevant to be taken further for the decision-making matrix.

TABLE I: LIST OF FACTORS AND FREQUENCY OF REPETITION

\begin{tabular}{|l|l|l|l|}
\hline$\#$ & Criteria & $\begin{array}{l}\text { Freq. of } \\
\text { Repetition }\end{array}$ & $\begin{array}{l}\text { Cumulative } \\
\text { \% }\end{array}$ \\
\hline $\mathbf{1}$ & Cost & 20 & $16.4 \%$ \\
\hline $\mathbf{2}$ & Productivity & 13 & $27.0 \%$ \\
\hline $\mathbf{3}$ & Height & 12 & $45.1 \%$ \\
\hline $\mathbf{4}$ & environmental safety & 10 & $53.3 \%$ \\
\hline $\mathbf{5}$ & Safety of operator & 10 & $53.3 \%$ \\
\hline $\mathbf{6}$ & maintenance ease & 9 & $60.7 \%$ \\
\hline $\mathbf{7}$ & site congestion and accessibility & 9 & $68.0 \%$ \\
\hline $\mathbf{8}$ & electricity consumption & 8 & $74.6 \%$ \\
\hline $\mathbf{9}$ & installation ease & 7 & $80.3 \%$ \\
\hline $\mathbf{1 0}$ & availability of labour & 6 & $85.2 \%$ \\
\hline $\mathbf{1 1}$ & Experience & 5 & $89.3 \%$ \\
\hline $\mathbf{1 2}$ & duration of project & 4 & $92.6 \%$ \\
\hline $\mathbf{1 3}$ & availability of equipment & 3 & $95.1 \%$ \\
\hline $\mathbf{1 4}$ & availability of spare part & 3 & $97.5 \%$ \\
\hline $\mathbf{1 5}$ & lead time & 3 & $100.0 \%$ \\
\hline & & & \\
\hline
\end{tabular}

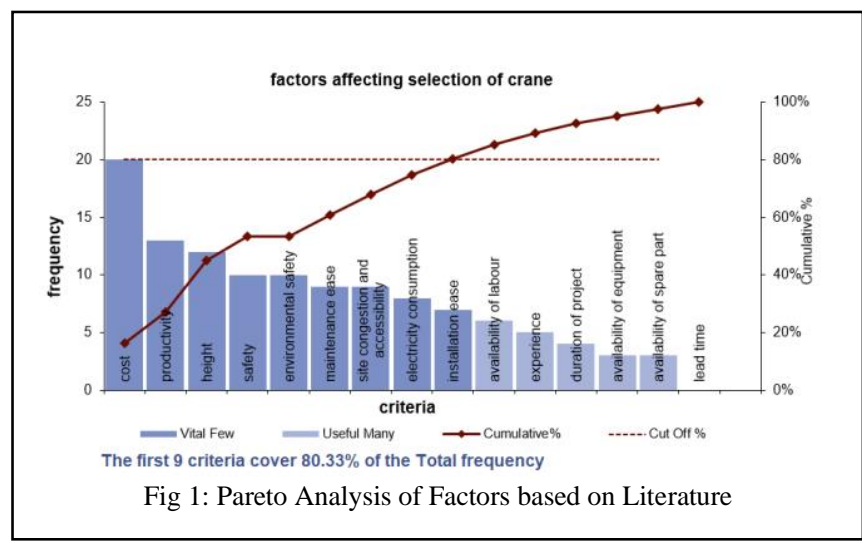

Since the frequency of each factor has been considered a measure of importance of that factor, the relative frequency of that factor has been considered as the weightage of the factor. It is to be noted that it has been assumed in this seminar that frequency of occurrence is a measure of importance while it might not always be the case. Hence, mathematically speaking, in this case weightage can be calculated as shown in Table II. 
TABLE II: CALCULATION OF WEIGHTAGE OF EACH CRITERIA

\begin{tabular}{|l|l|l|l|}
\hline$\#$ & Criteria & frequency & $\begin{array}{l}\text { Relative } \\
\text { frequency }\end{array}$ \\
\hline $\mathbf{1}$ & Cost & 20 & 0.2 \\
\hline $\mathbf{2}$ & Productivity & 13 & 0.13 \\
\hline $\mathbf{3}$ & Height & 12 & 0.12 \\
\hline $\mathbf{4}$ & environmental safety & 10 & 0.10 \\
\hline $\mathbf{5}$ & Safety of operator & 10 & 0.10 \\
\hline $\mathbf{6}$ & maintenance ease & 9 & 0.09 \\
\hline $\mathbf{7}$ & site congestion and accessibility & 9 & 0.09 \\
\hline $\mathbf{8}$ & electricity consumption & 8 & 0.08 \\
\hline $\mathbf{9}$ & installation ease & 7 & 0.07 \\
\hline
\end{tabular}

TABLE III: CALCULATION OF CRANE CyClE

\begin{tabular}{|c|c|c|c|c|}
\hline $\begin{array}{c}\text { Alter- } \\
\text { natives }\end{array}$ & $\begin{array}{c}\text { Total } \\
\text { crane cycle } \\
\mathbf{T}_{\mathbf{i j}}(\mathbf{m i n})\end{array}$ & $\begin{array}{c}\text { crane cycles } \\
\text { required } \\
\text { (nos.) }\end{array}$ & $\begin{array}{c}\text { Total time } \\
\text { taken }(\mathbf{m i n})\end{array}$ & $\begin{array}{c}\text { Total time } \\
\text { taken }(\mathbf{h r})\end{array}$ \\
\hline $\mathbf{A 1}$ & 3.260787 & 183.33 & 597.81 & 9.96 \\
\hline $\mathbf{A 2}$ & 3.427978 & 91.67 & 314.23 & 5.24 \\
\hline $\mathbf{A 3}$ & 3.427978 & 91.67 & 314.23 & 5.24 \\
\hline $\mathbf{A 4}$ & 3.427978 & 91.67 & 314.23 & 5.24 \\
\hline $\mathbf{A 5}$ & 3.056319 & 91.67 & 280.16 & 4.67 \\
\hline
\end{tabular}

\section{B. Calculation of Productivity}

Based on the mathematical relations provided by [20] in their research, the productivity of the available tower crane has been determined. Here, the productivity includes only the time taken by the crane itself and ignores the duration of loading and unloading the hook. The latter as per discussions at site is the greater time-consuming task but has been ignored in the study since it remains constant for the alternatives. [21] A source and destination point has been fixed at site and crane cycle has been calculated to determine time taken to hoist 55 cum of concrete. The alternatives A2 to A5 use a 1.5ton bucket for carriage of concrete, A1 can use only 0.8 ton due to the limited capacity of the equipment. The crane cycle obtained for each equipment has been tabulated in Table III.

\section{Review of Multicriteria Decision Making Techniques}

Considering the papers studied, methods such as Analytical Hierarchy Process (AHP), TOPSIS, Preference Ranking Organization METHod for Enrichment of Evaluations (PROMETHEE) and ELimination Et Choice Translating REality (ELECTRE) III have been employed in order of preference.

The advantage of the TOPSIS model includes that the user could easily comprehend the model and requires minimum amount of data for carrying out the decision-making process. In case of TOPSIS, the weightage could be either assigned directly to the matrix or obtained through pair-wise comparison as undertaken in AHP.

Since in this paper, the criteria considered are mostly quantitative, weightage has been derived from papers studied and further suggestions on pairwise comparison of factors, parameter and function type by the decision maker are absent, TOPSIS is the most suitable technique for evaluation of the alternatives.

Another distance-based method, VIKOR has been used in the paper in order to analyze the alternative. Unlike TOPSIS, VIKOR employs Manhattan distance for determination of proximity of the alternative to the ideal and ignores the distance from the negative ideal. Further, VIKOR also provides a set of compromised solutions in case the ranked alternatives fail to comply with a given set of criteria.

\section{Indentification of Research Gap}

While the study on tower crane, its appropriate selection and optimization is available, there is limited study focusing on operation of tower crane within the Indian context. Further the study does not include both the selection and productivity calculation of the crane. Hence, this paper has attempted to create a holistic framework for selection of tower crane.

\section{ANALYSIS OF TOWER CRANE ALTERNATIVES}

The alternatives shortlisted are: A1: Mobile TC, A2: Flat Top Rail Mounted TC, A3: Flat Top Fixed Base TC, A4: Flat Top Climbing Base TC, A5: Luffing Jib with Fixed Base. The criteria include C1 cost (lacs), C2 productivity (hr), C3 environmental safety (with or without diesel), C4 safety of operators, C5 ease of maintenance, C6 performance in congested site, C7 electricity consumption (kVA), C8 ease of installation and C9 area covered by the crane $\left(\mathrm{m}^{2}\right)$. Scoring of $\mathrm{C} 4,5,6$ and 8 is done at a scale of $1-5$ where 5 is max score.

\begin{tabular}{|l|l|l|l|l|l|l|l|l|l|}
\hline & C1 & C2 & C3 & C4 & C5 & C6 & C7 & C8 & C9 \\
\hline A1 & 26.5 & 9.96 & 1 & 5 & 5 & 2 & 12.5 & 5 & 1950 \\
\hline A2 & 42 & 5.24 & 0 & 1 & 2 & 1 & 33.5 & 2 & 2140 \\
\hline $\mathbf{A 3}$ & 42 & 5.24 & 0 & 3 & 4 & 3 & 33.5 & 4 & 1530 \\
\hline $\mathbf{A 4}$ & 42 & 5.24 & 0 & 2 & 3 & 4 & 33.5 & 3 & 1530 \\
\hline A5 & 65 & 4.67 & 0 & 4 & 1 & 5 & 33.5 & 1 & 1530 \\
\hline
\end{tabular}

\begin{tabular}{|c|l|l|l|l|l|l|l|l|l|}
\hline & $\min$ & $\min$ & $\min$ & $\max$ & $\max$ & $\max$ & $\min$ & $\max$ & $\max$ \\
\hline $\mathrm{W}$ & 0.2 & 0.13 & 0.1 & 0.1 & 0.09 & 0.09 & 0.08 & 0.07 & 0.06 \\
\hline & & & & & & & & & \\
\hline ideal & 26.5 & 4.67 & 0 & 5 & 5 & 5 & 12.5 & 5 & 2140 \\
\hline worst & 65 & 9.96 & 1 & 1 & 1 & 1 & 33.5 & 1 & 1530 \\
\hline
\end{tabular}

Where $\mathrm{W}=$ weightage. Through this method a matrix of $\mathrm{m}$ alternatives and $\mathrm{n}$ criteria is constructed which is normalized as per relation: $\mathbf{r}_{\mathrm{ij}}=\mathbf{x}_{\mathrm{ij}} / \mathbf{s q} \operatorname{root}\left(\mathbf{s u m}, \mathrm{i}=\mathbf{1} \ldots \mathrm{m}\right.$ of $\left.\mathbf{x}_{\mathrm{ij}}{ }^{2}\right)$

TABLE V: NORMALIZED MATRIX WITH WEIGHTAGE

\begin{tabular}{|l|l|l|l|l|l|l|l|l|l|}
\hline & C1 & C2 & C3 & C4 & C5 & C6 & C7 & C8 & C9 \\
\hline A1 & 0.14 & 0.00 & 0.00 & 0.07 & 0.06 & 0.02 & 0.08 & 0.05 & 0.03 \\
\hline A2 & 0.08 & 0.06 & 0.05 & 0.01 & 0.02 & 0.01 & 0.00 & 0.02 & 0.03 \\
\hline $\mathbf{A 3}$ & 0.08 & 0.06 & 0.05 & 0.04 & 0.05 & 0.04 & 0.00 & 0.04 & 0.02 \\
\hline $\mathbf{A 4}$ & 0.08 & 0.06 & 0.05 & 0.03 & 0.04 & 0.05 & 0.00 & 0.03 & 0.02 \\
\hline $\mathbf{A 5}$ & 0.00 & 0.07 & 0.05 & 0.05 & 0.01 & 0.06 & 0.00 & 0.01 & 0.02 \\
\hline ideal & 0.14 & 0.07 & 0.05 & 0.07 & 0.06 & 0.06 & 0.08 & 0.05 & 0.03 \\
\hline worst & 0.00 & 0.00 & 0.00 & 0.01 & 0.01 & 0.01 & 0.00 & 0.01 & 0.02 \\
\hline
\end{tabular}

TABLE VI: CALCULATION OF DISTANCE

\begin{tabular}{|l|l|l|l|l|l|l|l|l|l|}
\hline \multicolumn{1}{|c|}{ from ideal } & \multicolumn{5}{|c|}{ di $+=\sqrt{ }$ (sum of squares for j=1,...,n of (vij-vj+)) } \\
\hline & C1 & C2 & C3 & C4 & C5 & C6 & C7 & C8 & C9 \\
\hline A1 & 0.00 & 0.07 & 0.05 & 0.00 & 0.00 & 0.04 & 0.00 & 0.00 & 0.00 \\
\hline A2 & 0.06 & 0.01 & 0.00 & 0.05 & 0.04 & 0.05 & 0.08 & 0.03 & 0.00 \\
\hline A3 & 0.06 & 0.01 & 0.00 & 0.03 & 0.01 & 0.02 & 0.08 & 0.01 & 0.01 \\
\hline
\end{tabular}




\begin{tabular}{|l|l|l|l|l|l|l|l|l|l|}
\hline A4 & 0.06 & 0.01 & 0.00 & 0.04 & 0.02 & 0.01 & 0.08 & 0.02 & 0.01 \\
\hline A5 & 0.14 & 0.00 & 0.00 & 0.01 & 0.05 & 0.00 & 0.08 & 0.04 & 0.01 \\
\hline \multicolumn{7}{|l|}{ from worst } \\
\hline & C1 & C2 & $\mathbf{C}$ (sum of squares for j=1,...,n of (vij-vj-)) \\
\hline A1 & 0.14 & 0.00 & 0.00 & 0.05 & 0.05 & 0.01 & 0.08 & 0.04 & 0.01 \\
\hline A2 & 0.08 & 0.06 & 0.05 & 0.00 & 0.01 & 0.00 & 0.00 & 0.01 & 0.01 \\
\hline A3 & 0.08 & 0.06 & 0.05 & 0.03 & 0.04 & 0.02 & 0.00 & 0.03 & 0.00 \\
\hline A4 & 0.08 & 0.06 & 0.05 & 0.01 & 0.02 & 0.04 & 0.00 & 0.02 & 0.00 \\
\hline A5 & 0.00 & 0.07 & 0.05 & 0.04 & 0.00 & 0.05 & 0.00 & 0.00 & 0.00 \\
\hline
\end{tabular}

decision-making systems more robust and at the same time should be validated against real-time decisions for evaluation of these systems.

\section{CONCLUSION}

From the consistency in results obtained from the three MCDM methods, it can also be concluded that TOPSIS can be employed for selection of tower cranes when direct assessments of the available alternatives with respect to the given criteria is too complex to be solved using human rationale alone. However, the selection of factors itself is a process that would be crucial in determining the appropriateness of the cranes.

Moreover, even though as per the given matrix, luffing jib is ranked the lowest, it is widely employed at sites where restriction is the governing criteria. Since relative frequency has been used as a determinant of weightage, the luffing jib ranks low in the given calculation. This also points out the importance of assessment of weightage by reliable authority who have the foresight to understand the requirements of the project.

Further, the evaluation cannot be entirely quantitative and requires input from regular users and professionals involved in the crane industry. The data pertaining parameters of installation, maintenance and site congestion was based on opinions of staff at site and the experts dealing with supplying of tower crane. This ranking on the basis if opinion appears convenient when dealing with 5 alternatives, however as the number of alternatives increase, it can be extremely confusing for the decision makers due to cognitive bias and logical inconsistency. In such cases a model such as AHP might be required to overcome this limitation.

\section{A. Future Scope}

This paper has attempted to evaluate the limited number of alternatives accessible to the author based on MCDM techniques that are widely used by scholars. It is needed that such a process is carried out by decision makers and the techniques modified based on the feedback received from the actual course of events to produce that are more robust and realistic. Such models can not only be extended towards selection of tower cranes but also for equipment where the decision maker is prone to face a large number of criteria for performance other than the component of cost and has numerous options available. A better decision-making strategy is essential for proper utilization of any equipment.

\section{ACKNOWLEDGMENT}

I wish to thank Prof. Dr. V.K. Paul (Dean P\&D) for his guidance throughout the study. I also extend my gratitude to Asst. Prof. Luke Judson for his constant support and $\mathrm{Mr}$. Kuldeep Kumar for his valuable inputs. I am also grateful to senior site supervisors and crane operators at Mahagun Manorial at NOIDA and BGSCTPL site at Dwarka for their time and support to carry out the case study.

\section{REFERENCES} linguistic scale-based data or opinions. Researchers have used fuzzy sets in these methods of TOPSIS and VIKOR to overcome this limitation of the method. This modification is helpful and is a better representation of real-world data. More research on this aspect can be considered to make the

[1] Gray, C. \& Little, J., 2006. A Systematic Approach to the Selection of an Appropriate Crane for a Construction Site. Construction Management and Economics, July, 3(2), pp. 121-144.

[2] Lee, D., Son, K. \& Kim, S., 2011. ANALYSIS OF OPERATION EFFICIENCY OF TOWER CRANE IN FORM WORK 
CONSTRUCTION FOR MULTI-FAMILY HOUSING. Seoul, International Association for Automation and Robotics in Construction.

[3] Espino, D. J., Castillo-Lopez, E., Rodriguez-Hernandez, J. \& CanterasJordana, C., 2014. A review of application of multi-criteria decision making methods in construction. Automation in Construction, Volume 45(Issue 1), pp. 151-162

[4] Arslan, M. Ç., Çatay, B. \& Budak, E., 2004. A Decision Support System for Machine Tool Selection. Journal of Manufacturing Technology Management, 15(1), pp. 101-109.

[5] Chinchore, N. D. \& Khare, P. R., 2014. Planning and Selection of Heavy Construction Equipment in Civil Engineering. International Journal of Engineering Research and Applications, 4(12), pp. 29-31

[6] Al-Hussein, M., Alkass, S. \& Moselhi, O., 2001. An Algorithm for Mobile Crane Selection and Location in Construction SItes. Construction Innovation, pp. 91-105.

[7] Chan, F., Ip, R. \& Lau, H., 2001. Integration of Expert System with Analytical Heirarchy Process for the Design of Material Equipment Handling Selection System. Journal of Material Processing Technology, 116(1), pp. 137-145.

[8] Goldenberg, M. \& Shapira, A., 2007. Systematic Evaluation of Construction Equipment Alternatives: A Case Study. Journal of Construction Engineering and Management, 133(1), pp. 72-85.

[9] Jariwala, S. \& Pitroda, J., 2014. A Critical Literature Review on Factors Affecting Selection of Construction Equipment. International Journal of Advanced Technology in Engineering and Science, 2(12), pp. 559-567.

[10] Karande, P. \& Chakraborty, S., 2013. Material Handling Equipment Selection Using Weighted Utility Additive Theory. Journal of Industrial Engineering, pp. 9-18.

[11] Dalalah, D., AL-Oqla, F. \& Hayajneh, M., 2010. Application of the Analytic Hierarchy Process (AHP) in Multi-Criteria Analysis of the Selection of Cranes. Jordan Journal of Mechanical and Industrial Engineering, 4(5), pp. 567-578.
[12] Qi, X., Zhou, X., Song, M. \& Li, F., 2011. Study on Selection and Optimization of Vertical Transportation Equipment for High-rise Construction. Advanced Materials Research, 168(I), pp. 2376-2381.

[13] Waris, M., Liew, M. S., Khamidi, M. F. \& Idrus, A., 2014. Criteria for the selection of sustainable onsite construction equipment. International Journal of Sustainable Built Environment, 3(1), pp. 96-110.

[14] Tuzkaya, G., Gülsün, B., Kahraman, C. \& Özgen, D., 2010. An integrated fuzzy multi-criteria decision making methodology for material handling equipment selection problem and an application. Expert Systems with Applications, 37(4), pp. 2853-2863.

[15] Momani, A. M. \& Ahmed, A. A., 2011. Material Handling Equipment Selection using Hybrid Monte Carlo Simulation and Analytic Heirarchy Process. International Journal of Industrial and Manufacturing Engineering, 5(11), pp. 2177-2182.

[16] Valli, P. \& Jeyasehar, A., 2012. GENETIC ALGORITHM BASED EQUIPMENT SELECTION METHOD FOR CONSTRUCTION PROJECT USING MATLAB. Int. J. Optim. Civil Eng, 2(235-246), p.

[17] Casals, M., Forcada, N. \& Roca, X., 2003. A Methodology to Select Construction Equipment. Automation in Construction, pp. 571-576

[18] Komljenovic, D. \& Kecojevic, V., 2009. Multi-attribute selection method for materials handling equipment. International journal for Industrial and Systems Engineering, 4(2), pp. 151-173

[19] Prasad, K., Zavadskas, K. E. \& Chakraborty, S., 2015. A Software Prototype for Material Handling Equiment Selection for Construction Sites. Automation in Construction, pp. 120-131.

[20] Abdelmegid, M. A., Shawki, K. M. \& Abdel-Khalek, H., 2015 . GA optimization model for solving tower crane location problem in construction sites. Alexandria Engineering Journal, pp. 11-19

[21] Alkriz, K and Mangin, J-C (2005) A new model for optimizing the location of cranes and construction facilities using genetic algorithms. 2, 981-91. 